\title{
Inclusão socioeducativa \\ na escola: avaliação do \\ processo e dos alunos
}

- Neli Klix Freitas*

\section{Resumo}

A proposta do artigo é a de apresentar questões teórico-conceituais referentes às Políticas Públicas Inclusivas e refletir sobre a avaliação de crianças com necessidades educativas especiais em classes de educação inclusiva. $O$ artigo foi elaborado com base na pesquisa sobre o tema desenvolvida pela autora. $O$ direito ao ensino regular tem possibilitado às crianças com necessidades educativas especiais o desenvolvimento de funções cognitivas e sociais, e aos professores envolvidos nesse processo, a busca de qualificação em várias áreas do conhecimento. $O$ artigo também aborda a avaliação, que deve ser repensada de modo crítico. Atenção especial é dada às contribuições teóricas de Vygotsky e suas implicações para o debate sobre inclusão na educação e na sociedade.

Palavras-chave: Legislação e inclusão. Educação inclusiva. Alunos com necessidades educativas especiais. Avaliação. Teoria de Vygotsky.

\section{Social and educational inclusion: the process and the students' evaluation Abstract}

The purpose of this article is to present theoretical and conceptual questions about Public Inclusive Policies and to reflect upon evaluation of children with special educational needs. The article was based on the results of the author's research on this subject. The right to regular education has made possible for children with special educational needs to develop cognitive and social functions and for teachers who are involved in this process, to seek for qualification in several fields of knowledge. The article also mentions evaluation, which needs a critic reflection. Special attention is given to Vygotsky's theoretical contributions, and to their implications for the discussions on education and society inclusion.

Keywords: Policies and inclusion. Inclusive education. Teachers. Children with special educational needs. Evaluation. Vygotsky's theory.

\footnotetext{
* Doutora em Psicologia, Pontifícia Universidade Católica, SP; Professora da Universidade do Estado de Santa Catarina, SC. E-mail: neliklix@terra.com.br
} 


\section{La inclusión socio-educativa: evaluación del proceso y de los alumnos Resumen}

La propuesta del artículo es presentar cuestiones teóricas y conceptuales sobre las Políticas Públicas de Inclusión y pensar sobre la evaluación de alumnos portadores de necesidades educativas particulares, en clases de educación inclusiva. El artículo fue elaborado a partir de la pesquisa de la autora sobre el tema. El derecho a la enseñanza regular tiene ofertado a los educandos con necesidades educativas especiales el desenvolvimiento de funciones cognitivas y sociales, y a los docentes la búsqueda de calificación en distintas áreas del conocimiento. La evaluación debe ser críticamente pensada. Particular atención es dada al aporte teórico de Vygotsky y sus implicaciones para el debate sobre la inclusión en educación y sociedad.

Palabras clave: Legislación y inclusión. Educación inclusiva. Docentes. Alumnos con necesidades educativas especiales. Evaluación. Teoría de Vygotsky

\section{Introdução}

Nas diferentes áreas do conhecimento estamos diante de grandes transformações educacionais: mudanças nos parâmetros curriculares nacionais, na legislação referente à acessibilidade à escola, mudanças na obrigatoriedade do ensino, na fundação de um outro tipo de escola. Existe o direito universal à educação e à escola para todos os brasileiros, assim como as escolas brasileiras têm a obrigatoriedade legal de acolher a todos.

Entretanto, se existe alguma coisa que pode ser nomeada como mudança no cenário atual da educação, isso não se refere apenas à nomenclatura, nem somente à legislação. Esta mudança relaciona-se com a possibilidade de questionar modelos, argumentos, formas de avaliação, paradigmas e de propor outros novos, originais, impensáveis até o momento. Várias questões surgem nessa perspectiva, dentre as quais salienta-se a avaliação em tempos de educação inclusiva.

A aceitação das diferenças entre as pessoas inclui a preocupação com o outro, o respeito, o reconhecimento, a tolerância. Para ampliar a reflexão aponta-se: essas questões são reais, ou trata-se de mais uma oposição binária entre inclusão e exclusão?

Parece existir certo consenso acerca da idéia de que já não há um único modo de compreender o que é a educação, nem como a escola deve lidar com os alunos com necessidades educativas especiais, assim como definir quais são os paradigmas e modelos de uma postura inclusiva. Entretanto, ainda permanece o discurso de que algumas crianças que apresentam dificuldades para aprender não deveriam estar na escola, ou nas mesmas classes do que aquelas que não apresentam dificuldades para aprender.

A educação inclusiva permite lançar o olhar para múltiplas direções. $\bigcirc$ que ocorre em nossos tempos é que alguns matizes de diferenças até aqui ignorados, ou ocultos tem sido repensados, pelo menos não negados, talvez porque a legislação 
tenha estabelecido critérios mais rigorosos, ou por outras razões. As formas de diferenças do corpo, de aprendizagem, de linguagem, de movimento, de ser, de vestirse, de viver devem ser vistas não como um atributo, uma propriedade, uma característica das pessoas com dificuldades para aprender, mas como uma possibilidade para ampliar a compreensão acerca da intensidade das diferenças humanas. Essas afirmativas adquirem relevância quando se fala sobre avaliação na escola, particularmente na escola com educação inclusiva.

\section{Inclusão socioeducativa: mapeando a legislação}

Existe consenso entre a maioria dos países do mundo há mais de meio século, como estipulam o artigo 26 da Declaração Universal dos Direitos Humanos, em 1948 (BRASIL, 1998a), a Convenção dos Direitos da Criança, em 1989 (NAÇÕES UNIDAS, 2004), e as Diretrizes da Primeira Conferência Mundial sobre a Educação, reunida em Jomtien, Tailândia, em 1990; o Fórum Mundial sobre a Educação, realizado em Dakar, Senegal (2000), Estatuto da Criança e do Adolescente (BRASIL, 1990) de que a educação é um direito humano inalienável, que proporciona aos cidadãos o conhecimento necessário para viver com dignidade. Também há unanimidade nas questões econômicas, sociais, políticas, culturais e sanitárias de que não haverá desenvolvimento expressivo nestes setores, sem um investimento na educação (BIANCHETTI, 1995; CARDOSO, 2003; SASSAKI, 1997). Investir em educação constitui a primeira etapa indispensável para assegurar os direitos humanos, tais como a postura de aceitação das desigualdades e da diversidade, a redução da pobreza, a aceitação de avanços na saúde e nutrição, o controle de crescimento demográfico, dentre outros.

Abordando mais especificamente as questões da educação inclusiva tem-se um histórico amplo de várias significações, que assinala registros de resistência à aceitação social dos portadores de necessidades educativas especiais. Até meados do século XVIII algumas práticas eram executadas, tais como abandono, afogamentos, asfixia, dentre outras. Ao final do século XVIII e nas três primeiras décadas do século XIX teve início, nos países escandinavos e na América do Norte, o período de institucionalização especializada de pessoas com deficiências, nomenclatura adotada na época. A partir daí surgiu a Educação Especial. A sociedade tomou consciência da necessidade de atender as pessoas denominadas como deficientes, mas a forma de atendimento priorizava um caráter assistencialista. A assistência era prestada em Centros Especializados, nos quais as pessoas recebiam atendimento de vários profissionais: médicos, psicólogos, psicopedagogos, assistentes sociais, dentre outros.

No século XX a desinstitucionalização começou a ocorrer, com programas escolares para deficientes mentais. Os serviços especiais foram diversificados, e as classes especiais passaram a integrar o contexto escolar. No Brasil, as classes especiais foram criadas entre 1960 e 1965, em todo o país, para pessoas excepcionais. Este era o termo empregado exclusivamente para as pessoas que freqüentavam as classes especiais. As classes especiais desta época contribuíram novamente para a segregação e exclusão. A partir de 1980, a nomenclatura "deficientes" passou para "pessoas portadoras de deficiência". A partir de 1986 houve a substituição da mesma, de pessoas portadoras de deficiência, bem como de excepcionais, específica das classes especiais, para pessoas 
com necessidades educativas especiais. Mas, a adoção desta terminologia foi um processo lento. Ainda hoje em dia é possível ouvir referências aos "deficientes", aos "excepcionais", apesar da existência legal das nomenclaturas oficiais. Tal questão pode ser atribuída à lentidão na aceitação real da educação inclusiva, bem como nas resistências às mudanças no cotidiano da educação (CARDOSO, 2003).

No ano de 1986 surgiu também a proposta de integração educativa. $\bigcirc$ ensino dos alunos portadores de necessidades educativas especiais poderia ser realizado no contexto da escola regular. Cardoso (2003, p.19-20) explicita que,

[...] esta nova concepção não nega que os alunos tenham problemas em seu desenvolvimento. No entanto, a ênfase consiste em oferecer ao aluno uma mediação. A finalidade primordial é analisar o potencial de aprendizagem, como sujeito integrado em um sistema de ensino regular, avaliando ao mesmo tempo quais os recursos que necessita para que sua evolução seja satisfatória. $\bigcirc$ conceito necessidades educacionais especiais remete às dificuldades de aprendizagem e também aos recursos educacionais necessários para atender essas necessidades e evitar dificuldades.

Os portadores de necessidades educativas especiais passam a ser vistos como cidadãos, com direitos e deveres de participação na sociedade. A educação de pessoas portadoras de necessidades educativas especiais trilhou um caminho que, em uma fase inicial foi eminentemente assistencial, até chegar ao que hoje se denomina de educação inclusiva.

No Brasil, mudanças começaram a ocorrer na nomenclatura: de "alunos excepcionais" evoluiu para "alunos com necessidades educativas especiais", o que ocorreu em 1986, pela Portaria CENESP/MEC, n 69 (BRASIL, 1986), ainda que efetivamente não houvesse um avanço expressivo na inserção destes alunos no ensino regular.

A Constituição Brasileira de 1988, também trata deste assunto. No capítulo III, da Educação, da Cultura e do Desporto, Artigo 205, prescreve que "a educação é direito de todos e dever do Estado e da Família." Em seu artigo 208, prevê mais especificamente que "[...] o dever do Estado com a educação será efetivado mediante a garantia de: [...] atendimento educacional especializado, preferencialmente na rede regular de ensino" (BRASIL, 1988).

A Lei de Diretrizes e Base da Educação Nacional (LDB) mais recente, Lei nº 9.394 (BRASIL, 1996), conceitua e orienta a abordagem inclusiva para os sistemas regulares de ensino dando ênfase, no capítulo $V$, especialmente à Educação Especial. Referencia no artigo 59, que "[...] os sistemas de ensino assegurarão aos educandos com necessidades especiais: currículos, métodos, técnicas, recursos educativos e organização específica, para atender às suas necessidades".

Anteriormente, no ano de 1994 mais precisamente em 10 de junho, na cidade de Salamanca, na Espanha ocorreu a Conferência Mundial de Educação, patrocinada 
pelo governo espanhol e pela UNESCO, com representantes de 92 países e 25 organizações internacionais. Nesta conferência foi reafirmado o compromisso com a educação para todos e elaborada uma declaração, conhecida na História da Educação como a Declaração de Salamanca, que apresenta metas de ação na sociedade. Esta é considerada um marco na documentação em favor da educação inclusiva:

[...]as escolas regulares com orientação para a educação inclusiva são o meio mais eficaz no combate às atitudes discriminatórias, propiciando condições para o desenvolvimento de comunidades integradas, base da construção da sociedade inclusiva e obtenção de uma real educação para todos (DECLARAÇÃO ..., 1994, p. 9).

Após inúmeras pressões políticas, sociais e educativas, atualmente tem-se inúmeras medidas legislativas que atestam o direito às pessoas com necessidades educativas especiais de freqüentarem as instituições de ensino, fato que cresce a cada dia. Conforme a Organização das Nações Unidas para a Educação, a Ciência e a Cultura (UNESCO), o Brasil é o país da América Latina que mais insere alunos com necessidades especiais em escolas regulares, seguido de México e Chile (BRASIL, 1998b).

No entanto, a política de inclusão de alunos que apresentam necessidades educativas especiais baseia-se em fatores mais abrangentes do que somente os legislativos. Uma das questões centrais reside em como tornar compatível esta realidade heterogênea com os esquemas, as tradições e as inércias profissionais de alguns professores, que ainda fundamentam suas práticas em modelos que não estão preparados para trabalhar a diversidade e a diferença. Tentam manter propostas de ensino a partir da perspectiva de homogeneização. É então um desafio, que muito passa pela estrutura curricular, incluindo métodos e técnicas de ensino, bem como a questão da avaliação. Uma das questões que se apresenta é: como proceder quanto à avaliação neste processo de inclusão? Em seqüência, pode-se perguntar: deve-se avaliar, e como proceder, para fugir dos rótulos, das evoluções nos diagnósticos já padronizados, promovendo uma análise complexa e reflexiva desse procedimento escolar?Trata-se de uma mudança radical.

Esta mudança implica ainda uma atenção às diferenças individuais e ao contexto de aprendizagem, uma flexibilização da organização curricular, das estratégias de ensino, da gestão dos recursos e da avaliação, a fim de proporcionar um desenvolvimento maximizado de todos os alunos, de acordo, com as suas necessidades individuais (ALMEIDA, 2003, p. 67).

\section{A inclusão em educação e o processo de avaliação: questões teórico-conceituais, problematização e reflexões}

A visão da escola inclusiva impõe a demolição dos discursos educacionais que excluem as diferenças. A fronteira que separa de forma nítida aqueles olhares que continuam pensando que o problema da educação escolar está na anormalidade, no anormal, bem 
como daqueles que pensam o oposto: os que consideram a normalidade, a norma, o normal como o problema em questão é que deveria ser colocado sob suspeita. Trata-se de representações que se apresentam como científicas e acadêmicas, vigiando cada desvio, descrevendo cada detalhe das patologias, cada vestígio da normalidade, suspeitando de toda deficiência com a conhecida afirmação de que "algo está errado no sujeito, que possuir uma deficiência é um problema" (SKLIAR, 2003, p. 18).

Essas considerações remetem-nos a lançar outros olhares, talvez menos vigilantes, que tenham de inverter a discussão, fazendo do normal, da norma o problema que deve ser colocado em questão. Esses olhares têm muito a oferecer à educação em geral, produzindo a desmistificação do normal, questionando os parâmetros instalados na pedagogia sobre o que deve ser correto, e essa afirmativa refere-se intensamente à avaliação: como realizar a avaliação do ensino e da aprendizagem em educação inclusiva? A avaliação sempre teve um papel de destaque na educação. Muitas vezes, de preocupação. Na grande maioria das escolas, uma imposição. No caso de crianças com necessidades educativas especiais, quais são os procedimentos mais recomendados no que se refere à avaliação? Ou, como avaliar alunos de classes com educação inclusiva? Há múltiplos olhares, mas certamente há aqueles olhares que não abrem mão da avaliação do aluno. Esses olhares podem solapar a pretensão altiva da normalização, que não é mais do que a violenta imposição de uma suposta identidade, única, fictícia e sem fissuras, daquilo que é pensado como o normal (SILVA, 1997; SKLIAR, 2003).

Normalizar significa escolher arbitrariamente uma identidade, e fazer dela a única identidade possível, a única identidade verdadeira e adequada. Nessa perspectiva, os portadores de necessidades educativas especiais não encontram um espaço de aceitação.

No Brasil, uma vez que a educação inclusiva despontou como realidade não é possível ignorar que há necessidade de repensar a avaliação. A avaliação de crianças com necessidades educativas especiais deve incluir a adaptação à escola, a interação social, principalmente. Questiona-se se esta questão pode ser ignorada, e se a avaliação deve ser padronizada. São questionamentos que carregam em seu bojo tanto a aceitação das diferenças, quanto reflexões sobre a capacitação dos professores, sobre os modelos pedagógicos vigentes e procedimentos de avaliação, sobre a adequação das escolas e também, sobre as responsabilidades das famílias nesse processo. Assim, não se trata apenas de uma questão legal, que é real, mas que se amplia pelas malhas da rede educacional, nas distintas áreas do conhecimento. Se por um lado o acesso dos portadores de necessidades educativas especiais às escolas de ensino regular cresce a cada dia, por outro ainda são precárias as instalações físicas, a oferta de material didático-pedagógico adequado e a capacitação de professores, para efetivar uma educação inclusiva de qualidade. Ao avaliar o processo da educação inclusiva estas questões devem ser consideradas, juntamente com a formação de professores e propostas curriculares.

Vygotsky, expoente do Sócio-Interacionismo postula que o professor deve ser um mediador entre o sujeito que aprende e o conhecimento. "Mediar consiste nas ações de um agente intermediário em uma relação" (VYGOTSKY, 1987, p. 96). O autor 
trabalha com a noção de que a relação homem-mundo não é uma relação direta, mas fundamentalmente mediada.

Nessa perspectiva não há espaço para a transmissão de conhecimentos sem a presença dos signos, dos símbolos e da cultura, considerados como agentes mediadores e ferramentas úteis no processo de aquisição do conhecimento. "Os signos passam a ser compartilhados pelos membros do grupo social, permitindo a comunicação entre os indivíduos e a interação social" (VYGOTSKY, 1984, p. 102). Compete ao professor conhecer essa questão, para adequar posturas e métodos a um modelo que coincide com práticas educativas atualizadas.

Com a educação inclusiva, a mediação adquire um caráter de grande importância, uma vez que abrange três questões imprescindíveis ao processo de construção do conhecimento: "o aluno, como o sujeito que aprende; o professor como mediador; a cultura, os signos como ferramentas a serem empregadas. $\bigcirc$ princípio que regula a dinâmica implícita nessa trama conceitual é a interação social" (VYGOTSKY, 1987, p. 161). Trata-se de um modelo pertinente em tempos de educação inclusiva, onde a interação é um processo essencial.

Ao longo do processo de desenvolvimento, o ser humano deixa de necessitar das marcas externas e "passa a utilizar signos internos, isto é, representações mentais, que substituem os objetos do mundo real" (OLIVEIRA, 2001, p. 35).

Desse modo, crianças com necessidades educativas especiais necessitam de ações mediadas, dos agentes mediadores, da postura de mediação do professor, sempre em interação com crianças sem necessidades educativas especiais. Na medida em que esse processo se consolida, alunos sem necessidades educativas especiais tornam-se também mediadores para seus colegas com necessidades educativas especiais, e a educação se reconfigura. Trata-se de novos tempos, que exigem outras posturas, nas quais a interação social é imprescindível. Mas, essa proposta pressupõe uma dinâmica de aceitação de diferenças, em uma postura ética solidária (SKLIAR, 2003).

Larrosa e Skliar (2002) sugerem uma pedagogia do diálogo, da harmonia, da empatia, não para terminar com as diferenças, mas para manter a tensão entre elas, compreendendo que é da tensão que emerge a criação de algo novo e a possibilidade de uma nova ordem, que subverte o caos. Em educação não se trata de caracterizar o que é a diversidade e quem a compõe, mas sim de compreender melhor como as diferenças nos constituem como seres humanos.

Questões inclusivas, sociais e educacionais pedem por novos olhares: olhares múltiplos para romper com a hegemonia epistêmica dos grandes saberes que, com seu olhar iluminista pretendem iluminar tudo. Busca-se olhares iluminados por novos focos e instrumentos que possam descer fundo na ordem implícita, penetrando no subjacente e no subjetivo. Trata-se de uma visão de escuta das vozes de uma ciência que, em sua busca transdisciplinar é capaz de gestar o novo, nesse movimento de olhar para a educação sob novos ângulos (MUNIZ REZENDE, 1993). 
Não há um modelo único para a educação, assim como cada ser humano é diferente do outro. Uma visão hegemônica de educação, na qual todas as crianças aprendem do mesmo modo e no mesmo ritmo é uma utopia, um contido expansivo, que não pode ser aprisionado por nenhuma ideologia, nenhuma legislação. A multiplicidade representa o convite para a coragem de espiar por frestas inusitadas e conseguir ver outras dimensões da realidade.

Morin (2000) descreve que as interações entre indivíduos produzem a sociedade que, por sua vez, testemunha o surgimento da cultura, e que retroage sobre os indivíduos pela cultura. Para as escolas, essas afirmativas devem conduzir ao reconhecimento e à legitimação de novas práticas, reconhecendo e respondendo às necessidades diversificadas dos alunos, acomodando os diferentes estilos e ritmos de aprendizagem, assegurando uma educação de qualidade para todos e um processo de avaliação pertinente. Para isto há necessidade de currículos apropriados, tanto na formação de professores, quanto nas escolas com educação inclusiva. Longe de tratar-se de um problema específico da pedagogia, refere-se a todas as áreas do conhecimento e diluise pelas malhas da rede social. Afinal, em todas as áreas existe o processo de ensinoaprendizagem. Essas questões passam por mudanças institucionais, com adequação de estratégias de ensino, métodos, recursos e procedimentos de avaliação, seja na pedagogia, no ensino de artes, de matemática, dentre outras áreas.

A avaliação muitas vezes assume o papel de "dever cumprido". No entanto, a questão é mais abrangente. A avaliação da aprendizagem aparece associada às intenções educacionais que norteiam o ensino, mas estas devem ser claramente explicitadas. Os critérios que serão adotados deverão coincidir com um projeto, ou programa de ensino e que, no caso da educação inclusiva deve ser coerente com essa proposta. Não se pode confundir avaliação com medida. Podem ser utilizados alguns critérios como sendo indicadores da produção dos alunos, mas essa não pode adquirir uma dimensão comparativa, nem deve excluir os alunos com necessidades educativas especiais Em educação inclusiva, um dos princípios que deve nortear a avaliação é a adaptação, sempre visualizando a interação social como marco de referência. Adequar formas de avaliação supõe diversificálas, e isso significa também colocar à disposição dos alunos um conjunto amplo de ajuda e de apoio. Supõe a flexibilização dessas formas de apoio, de acordo com o momento em que os alunos possam receber o que necessitam. $\bigcirc$ ensino adaptativo que atende à inclusão deve aplicar o princípio de adaptação em um duplo sentido: de diversificação e de flexibilização, tanto no que se refere aos aspectos curriculares, quanto aos aspectos organizadores envolvidos na ação educacional, convertendo-os no eixo das ações da avaliação para o conjunto dos alunos (COLL; MARTIN; ONRUBIA, 2004).

A construção de uma proposta de avaliação em educação inclusiva deve ser vinculada a referenciais teóricos, às propostas curriculares e à legislação. A avaliação deve ser formativa, humana, inclusiva e coerente com o dinamismo da sociedade contemporânea, considerando as implicações para o aluno. Pode-se afirmar que o ensino, a aprendizagem e a avaliação são partes integrantes de um processo, que é o currículo, não devendo ser consideradas isoladamente (HERNÁNDEZ, 2001). 
A avaliação é uma questão político-pedagógica, e deve contemplar as concepções filosóficas de ser humano, de educação, de sociedade, o que implica em uma reflexão crítica e contínua da prática pedagógica da escola e de sua função social. Avaliar é acolher o aluno integralmente e, a partir daí decidir o que fazer, e como fazer. A ação avaliadora oferece subsídios para o educador refletir sobre sua práxis. (VASCONCELOS, 1994).

Em educação inclusiva há necessidade de inserir modelos de atenção à diversidade nas estruturas curriculares, e revisar a organização em sua totalidade, incluindo a avaliação. Um dos problemas que deve ser resolvido é o da adaptação do ensino à diversidade dos alunos e alunas que vivem nas sociedades pluralistas contemporâneas, e adequar políticas e ações que se apóiam no discurso da cultura pela diversidade. Trata-se de um desafio para os professores, particularmente nas classes de escolas com educação inclusiva, nas quais a interação social constitui um valor de primeira grandeza. Assim sendo, a avaliação deve contemplar a diversidade e a interação social. A diversidade deve ser pensada em princípios formativos, de crescimento individual e social. Avaliar implica em assumir reflexivamente as vivências e as experiências dos cidadãos de uma sociedade democrática.A avaliação passa a ser tanto da proposta de educação inclusiva em sua totalidade, quanto de todos os participantes (BLANCO; DUK, 1992).

Não existe evolução sem relações sociais e sem comunicação interpessoal, e essas considerações são particularmente importantes quando se pensa sobre avaliação e inclusão.

Na realidade, as pessoas com necessidades educativas especiais não podem ser descritas em termos de melhor e/ou pior, bem ou mal, superior ou inferior, maioria ou minoria, dentre outras considerações. $O$ fato de assinalar algumas necessidades educativas especiais como sendo diferenças volta a posicionar essas marcas, essas identidades como sendo opostas à idéia de norma, do normal e, então, daquilo que é pensado e fabricado como o correto, o positivo, o melhor (RODRIGUES, 2006).

Nessa perspectiva, cabe aos pesquisadores e estudiosos da educação questionar se o sistema tem tentado discutir a questão do outro nas políticas inclusivas, ou se o que preocupa é a obsessão pelo outro. Aqui, a avaliação deve buscar uma análise sobre a adaptação na escola, sobre as interações sociais que se processam no cotidiano escolar. Não parece um exagero afirmar que a escola atual ainda não se preocupa genuinamente com o outro, mas tem se tornado muitas vezes, obsessiva diante de cada fragmento da diferença em relação à mesmice.

Se o conhecimento é múltiplo, variado, não estanque; se o processo de transmissão de ensinamentos não fica restrito às escolas é de grande importância que se repense a formação de professores em diferentes níveis, para atuar no contexto dessa sociedade do conhecimento. É fundamental que sejam planejados processos formativos preparando o educador para uma atitude aberta frente ao e no mundo, pronto para aceitar o novo e a promovê-lo, ajudando a desenvolver nas pessoas com quem se relaciona um processo de subjetivação autônomo e singular. Em outras palavras, o educador 
deve estar preparado para o principal desafio que se lhe coloca hoje, que coincide com o que Guattari (1992) denomina como produzir novas potencialidades.

É uma possibilidade que se abre para o desenvolvimento e para o benefício de todos os alunos, com ou sem necessidades educativas especiais, nas escolas regulares de ensino trazendo consigo um conjunto de fatores, para que todos possam ser inseridos totalmente na sociedade em todos os seus segmentos: trabalho, lazer, saúde, dentre outros.

A inclusão se concilia com uma educação para todos e com um ensino especializado ao aluno, mas não se consegue implantar essa opção de inserção sem enfrentar um desafio ainda maior: o que recai sobre o fator humano. Os recursos físicos e os meios materiais para a efetivação de um processo inclusivo escolar de qualidade cedem um espaço de prioridade para o desenvolvimento de novas atitudes e formas de interação na escola, exigindo uma nova postura diante da aceitação das diferenças individuais, da valorização de cada pessoa, da convivência na diversidade humana, e da aprendizagem por meio da cooperação. Essas iniciativas promovem a adaptação das crianças, com e sem necessidades educativas especiais, enfatizando as interações sociais e a aprendizagem por meio da cooperação, na qual o professor é um mediador.

Não se trata de uma questão simples. $\bigcirc$ grande problema da integração não reside em diferentes concepções desse processo, mas no fato de que pessoas com necessidades educativas especiais ainda não são aceitas como sujeitos históricos e culturalmente contextualizados, apesar da legislação vigente no Brasil. Alunos com necessidades educativas especiais são aqueles que apresentam algum problema de aprendizagem ao longo de sua escolaridade, que exige uma atenção mais específica e maiores recursos educacionais do que aqueles oferecidos aos colegas de sua idade. Entretanto, não devem ser segregados. Compete às escolas recebê-los, respeitálos e proporcionar um ensino diversificado dispondo de recursos pedagógicos mais amplos (COLL; PALACIOS; MARCHESI, 1995).

A verdadeira educação, segundo Vygotsky (1984), consiste em despertar na criança aquilo que ela já possui dentro de si, ajudando-a a evolvir e a orientar o seu desenvolvimento em uma determinada direção. "Não uma direção de mão única, mas que contemple possibilidades de construção, desconstrução e reconstrução tal como ocorre na arte, mas sempre em interação social" (VYGOTSKY, 2003, p. 201). Uma das questões centrais que determina mudanças nada mais é do que a evidência do surgimento de novas luzes no bojo do desenvolvimento da humanidade, impregnada pela inclusão do tempo, da história e do sujeito como ator e construtor, precipitando crises conceituais. Trata-se de criticar sistemas de determinação, teorias e, pela própria impotência em satisfazer a realidade, o estabelecimento de caminhadas em direção a novas propostas, novas perspectivas.

\section{Considerações finais}

$O$ processo de desenvolvimento dos seres humanos segue a aprendizagem, mas vai além dela, ativando potenciais humanos. "A aprendizagem e o desenvolvimento, ainda que diretamente ligados não se processam simetricamente. $O$ desenvolvimento 
não é estanque, nem acompanha a aprendizagem como uma sombra acompanha o objeto que a projeta" (VYGOTSKY, 1984,p. 79). Existe uma dependência recíproca, complexa e dinâmica, que não pode ser explicada por uma única fórmula especulativa, nem apriorística. Para Vygotsky $(1984 ; 1987 ; 2003)$ a interação social é fundamental no desenvolvimento humano e na aprendizagem. Com base nessa afirmativa, a avaliação não pode ser definida de modo estanque, a priori,fechada em si mesma. A avaliação está integrada ao currículo e não pode ser dissociada do projeto educativo em sua totalidade, incluindo as políticas públicas, os projetos escolares, as propostas implícitas e a diversidade sócio-educacional.

A abertura das escolas para as diferenças tem a ver, dentre outras questões, com uma mudança radical nos processos de ensino e aprendizagem. Inclui uma proposta de ruptura entre as fronteiras existentes em diferentes disciplinas, entre saber e realidade. Isso implica em uma valorização da multiplicidade, da integração de saberes, das redes de conhecimento que, a partir daí se formam e se constituem, e que se inserem também nas novas tecnologias da informação. Assinala para a transversalidade das áreas curriculares e para a autonomia intelectual do aluno, autor do conhecimento e que, por isso mesmo, imprime valor ao que constrói. Esse processo não pode prescindir da interação social. Para Vygotsky (2003) o exercício pleno da criatividade está intimamente relacionado com o conhecimento "Nunca foi tão importante criar como em nossos tempos. Os mecanismos de controle não são fixos e padronizados, mas sim oscilantes e difusos, exigindo estratégias de enfrentamento capazes de ensejar múltiplas ações, singulares e versáteis." (VYGOTSKY, 2003, p. 53).

Vygotsky (1987) refere que existe uma interação entre o sujeito e o ambiente no processo de construção do conhecimento. Não se apreende a realidade diretamente, mas por reconstrução. Ensinar é, então, muito mais do que transmitir informações. Implica em mobilizar nos educandos o prazer de aprender. Avaliar é muito mais do simplesmente medir e comparar: implica em integrar, promover ações interativas e adaptativas a todas as crianças.

Muitas vezes, o educador se vê na posição de regular os desejos dos educandos - de todos - na escola inclusiva. Necessita decidir entre o prazer e a atividade intelectual para a qual é convocado, entre os espaços tabu e o cotidiano, entre o prazer e a racionalização. Entretanto, a legislação assinala que o professor necessita dominar suas restrições pessoais às diferenças, aliadas a domínios metodológicos e conhecimentos pedagógicos capazes de dar conta das distintas necessidades de seus alunos. É uma questão que desponta como realidade, vinculada à aceitação incondicional das diferenças entre as pessoas.

As implicações da educação inclusiva para os educadores é a construção de uma pedagogia da diferença, que não realce o exotismo, nem endemoninhe o outro, mas que busque locar a diferença tanto em sua especificidade, quanto em sua capacidade de formar posições para relações sociais e práticas culturais criticamente engajadas, ao estimular e valorizar a aprendizagem da criança como um ser que se expressa, que imagina e cria (HAMMER; MCLAREN, 1991). 
Espera-se que os professores sejam capazes de acolher a diversidade e estejam abertos às práticas inovadoras em sala de aula, que incluem conteúdos e práticas de diferentes áreas do conhecimento, que exercitem a avaliação direcionada para a adaptação e para a interação social entre diferentes estilos e aptidões para aprender. Há necessidade de adotar uma postura crítica sobre a avaliação diante das novas Políticas Públicas.

A educação inclusiva é uma possibilidade de romper as barreiras que inviabilizam a aceitação das diferenças entre as pessoas. Mas, trata-se de um processo complexo, que exige capacitação, exercício da tolerância, conhecimento, e que também necessita de avaliação permanente.

Diferentes terminologias percorrem hoje a trajetória rumo à diversidade, o que se presentifica na educação inclusiva. Implica no entanto, que cada país deve definir e adotar políticas públicas pensadas desde sua própria realidade, apropriadas ao contexto, à sociedade e à cultura, e o processo de avaliação não pode ser dissociado desses princípios norteadores.A educação inclusiva de qualidade, que vise realmente integrar diferenças deve convocar os governantes,os professores, as famílias e a sociedade como parceiros diante desses desafios.

\section{Referências}

ALMEIDA, A. S. Da educação especial à escola inclusiva. In: MOSQUERA, J. M; STOBAÜS, C. (Org.). Educação especial: em direção à educação inclusiva. Porto Alegre: EDIPUCRS, 2003.

BIANCHETTI, L. Aspectos históricos da educação especial. Revista Brasileira de Educação Especial, Piracicaba, v. 2, n. 3, p. 7-19, 1995.

BLANCO, R.; DUK, C. Adaptaciones curriculares y alumnos com necesidades especiales. Madrid: Ministério da Educación y Ciência, 1992.

BRASIL. Congresso. Câmara dos Deputados. Declaração universal dos direitos humanos, 1948-1978. Brasília, DF, 1998a.

. Constituição (1988). Constituição da República Federativa do Brasil. São Paulo: Atlas, 1988.

. Lei $n^{\circ}$. 8.069, de 13 de julho de 1990. Dispõe sobre o Estatuto da Criança e do Adolescente e dá outras providências. Diário Oficial [da República Federativa do Brasil], Brasília, DF, 16 jul. 1990. Disponível em: < http://www.planalto.gov.br/ ccivil_03/LEIS/L8069.htm>. Acesso em: 29 jul. 2008.

Lei $n^{\circ}$. 9.394, de 20 de dezembro de 1996. Estabelece as diretrizes e bases da educação nacional. Diário Oficial [da República Federativa do Brasil], Brasília, DF, 23 dez. 1996. 
BRASIL. Ministério da Educação e Cultura. Centro Nacional de Educação Especial. Portaria CENESP/MEC n. 69, de 28 de agosto de 1986. Diário Oficial [da República Federativa do Brasil], Brasília, DF, 1986.

- Ministério da Justiça. Coordenadoria Nacional para Integração da Pessoa Portadora de Deficiência. Boletim da UNESCO sobre educação inclusiva. Brasília, DF, 1998b.

CARDOSO, M. Aspectos históricos da educação especial: da exclusão à inclusão: uma longa caminhada. In: MOSQUERA, J. M.; STOBAÜS, C. (Org.). Educação especial: em direção à educação inclusiva. Porto Alegre: EDIPUCRS, 2003.

COLL, C.; MARTIN, E.; ONRUBIA, J. A avaliação da aprendizagem escolar: dimensões psicológicas, pedagógicas e sociais. In: COLL, C.; PALACIOS, J.; MARCHESI, A. Psicologia da educação escolar. Porto Alegre: Artes Médicas, 2004.

COLL, C.; PALACIOS, J.; MARCHESI, A. Desenvolvimento psicológico e educação. Porto Alegre: Artes Médicas, 1995.

DECLARAÇÃO de Salamanca e linha de ação sobre necessidades educativas especiais. Brasília, DF: CORDE, 1994.

GUATTARI, F. Caosmose: um novo paradigma estético. Rio de Janeiro: Ed. 34, 1992.

HAMMER R.; MC LAREN, P. Thinking the dialectic. London: Sage, 1991.

HERNANDEZ, F. Cultura visual, mudança educativa e projeto de trabalho. Porto Alegre: Artes Médicas, 2001.

LARROSA, J.; SKLIAR, C. (Org.). Habitantes de Babel: política e poética da diferença. Belo Horizonte: Atlântica, 2002.

MORIN, E. Os sete saberes necessários à educação do futuro. São Paulo: Cortez, 2000.

MUNIZ REZENDE, A. Bion y las bases del entendimiento humano.Buenos Aires: Paidós, 1993.

NAÇÕES UNIDAS (Brasil). Convenção sobre os Direitos das Crianças. Rio de Janeiro: UNIC Rio, 2004. Disponível em: http://www.onu-brasil.org.br/doc_crianca.php>. Acesso em: 28 jul. 2008.

OLIVEIRA, M. K. Vygotsky: aprendizado e desenvolvimento: o processo sócio-histórico. São Paulo: Scipione, 2001. 
RODRIGUES, D. Educação e diferença: valores e práticas para uma educação inclusiva. Porto: Porto Ed., 2006.

SASSAKI, R. Inclusão: construindo uma sociedade para todos. Rio de Janeiro: WVA, 1997.

SILVA, T. A política e a epistemologia do corpo normalizado. Rio de Janeiro: Espaço, 1997.

SKLIAR, C. Pedagogia (improvável) da diferença: e se o outro não estivesse aí?. Rio de Janeiro: DP\&A, 2003.

UNICEF (Brasil). Convenção sobre os Direitos da Criança. Nova York, 1989. Disponível em: <http://www.unicef.org/brazil/pt/resources_10120.htm>. Acesso em: 28 jul. 2008.

VASCONCELOS, C. Avaliação: concepção dialética e libertadora do processo de avaliação escolar. São Paulo: Libertad, 1994.

VYGOTSKY, L. S. A formação social da mente. São Paulo: Martins Fontes, 1987. . La imaginación y la arte en la infancia. 6. ed. Madrid: Akal, 2003. . Psicologia pedagógica. São Paulo: Martins Fontes, 1984.

Recebido em: 04/10/2007

Aceito para publicação em: 07/07/2008 